\title{
Pythagorean fuzzy time series model based on Pythagorean fuzzy c-means and improved Markov weighted in the prediction of the new COVID-19 cases
}

Sidong Xian ( $\nabla$ sidx@163.com )

Chongqing University of Posts and Telecommunications https://orcid.org/0000-0002-9871-4444

\section{Yue Cheng}

Chongqing University of Posts and Telecommunications

\section{Research Article}

Keywords: Pythagorean fuzzy sets, Pythagorean fuzzy time series, Pythagorean fuzzy c-means clustering, Imporved Markov weighted, COVID-19

Posted Date: June 29th, 2021

DOl: https://doi.org/10.21203/rs.3.rs-619944/v1

License: (c) (1) This work is licensed under a Creative Commons Attribution 4.0 International License.

Read Full License 


\section{Abstract}

Time series is an extremely important branch of prediction and the research on it plays an important guiding role in production and life. To get more realistic prediction results, scholars have explored the combination of fuzzy theory and time series. Although some results have been achieved so far, there are still gaps in the combination of $n$-Pythagorean fuzzy sets and time series. In this paper, a pioneering $n$ Pythagorean fuzzy time series model (n-PFTS) and its forecasting method ( $n$-IMWPFCM) is proposed to employ a n-Pythagorean fuzzy c-means clustering method (n-PFCM) to overcome the subjectivity of directly assigning membership and non-membership values, thus improving the accuracy of the partition the universe of discoure. A novel improved Markov prediction method is exploited to enhance the prediction accuracy of the model. The proposed prediction method is applied to the yearly University of Alabama enrollments data and the new COVID-19 cases data. The results show that compared with the traditional fuzzy time series forecasting method, the proposed method has better forecasting accuracy. Meanwhile, it has the characteristics of low computational complexity and high interpretability and demonstrates the superiority of this model from a realistic perspective.

\section{Full Text}

This preprint is available for download as a PDF. 